AIAA-2002-1728

\title{
Structural Efficiency Of Stitched Composite Panels With Stiffener Crippling
}

\author{
Dawn C. Jegley* \\ NASA Langley Research Center \\ Hampton, Virginia 23681
}

\begin{abstract}
The structural efficiency of blade-stiffened stitched specimens is compared to determine their weight saving potential if blades were allowed to buckle at less than or equal to design ultimate load. Analytical and experimental results from four configurations of crippling specimens are presented. Specimen skin and blades were held together with through-the-thickness stitches prior to curing. No mechanical fasteners were used for the assembly. Tests were conducted with and without low-speed impact damage. Failure modes are discussed. Finite element and experimental results agree for the response of the structures. For some specimen configurations, improved structural efficiency can be obtained by allowing stiffeners to buckle at design limit load rather than requiring that buckling not occur prior to design ultimate load. A parametric study is presented herein which describes the possible weight savings with this approach.
\end{abstract}

\section{Introduction}

One of NASA's goals is to reduce the cost of air travel by $50 \%$ in the next 20 years. To achieve this goal, NASA has been involved in the development of the technologies needed for future low-cost, light-weight composite structures for commercial transport aircraft. As a consequence of this effort, a stitched graphite-epoxy material system was developed with the potential for reducing the weight and cost of commercial transport aircraft wing structure. ${ }^{1}$ By stitching through the thickness of a dry graphite-epoxy material system, the labor associated with wing cover panel fabrication and assembly

* Senior Aerospace Engineer, Mechanics and Durability Branch. Senior Member, AIAA.

Copyright (C) 2002 by the American Institute of Aeronautics and Astronautics, Inc. No copyright is asserted in the United States under Title 17, U.S. Code. The U.S. Government has a royalty-free license to exercise all rights under the copyright claimed herein for Governmental purposes. All other rights are reserved by the copyright owner. can be significantly reduced. By stitching through the thickness of pre-stacked skin and then stitching stringers, intercostals and spar caps together with the skin, the need for mechanical fasteners is almost eliminated. This manufacturing approach reduces part count, and therefore, cost of the structure.

However, improving the material system is not the only way to improve structural efficiency. Traditionally wing cover panels were designed to resist buckling for loading that is less than design ultimate load. If this design requirement is changed to allow local buckling at design limit load (i.e. $2 / 3$ design ultimate load) without structural failure at a load less than design ultimate load, there is potential for lighter and more efficient structures. Structural efficiency is expressed in terms of weight versus load carrying capability. ${ }^{2-3}$ When a buckleresistant design approach is used the maximum load would be determined by the lowest of the loads corresponding to an allowable stress or strain or the minimum buckling load. However, since the purpose of this study is to evaluate the potential weight savings due to allowing panels to buckle prior to design ultimate load, the buckling load is not considered the design ultimate load. Instead, a specimen failure load is the maximum value for design ultimate load, but only if the buckling load is greater than the design limit load. In addition, a maximum stress failure criterion is used to predict the onset of damage in each element in the finite element model. However, damage tolerance is also an important issue in design of composite structures. A comparison is made between behavior of specimen with no damage and specimens first subjected to low-speed impact damage to evaluate the influence of damage on buckling behavior and failure.

\section{Test-Specimen Description}

The specimens, representative of stiffeners in a wing cover panel, were fabricated from stitched/resin film infused graphite-epoxy material. This material system allows minimizing the number of mechanical fasteners needed to assemble a wing box. Skin and blade-stiffeners were composed of layers of graphite material forms that were prekitted in nine-ply stacks using Hercules, Inc. AS4 fibers. Each nine-ply stack had a $\left[45 / 45 / 0_{2} / 90 / 0_{2} / 45 / 45\right]_{\mathrm{T}}$ laminate stacking sequence and was approximately 0.055 inches thick. Several stacks of the prekitted material were used to build up the desired thickness. Blades ranged in 
thickness from 0.11 to 0.44 inches. All material was stitched together using E. I. DuPont de Nemours, Inc. Kevlar thread. Stiffener flanges were stitched to the skin and no mechanical fasteners were used for joining. The specimens were fabricated using Hercules, Inc. 3501-6 epoxy in a Resin Film Infusion (RFI) process which is described in references 4 and 5. Material properties are shown in table 1. Specimens for this study were fabricated in four configurations of representative designs. Two configurations of X-shaped specimens (X1 and X2) and two configurations of T-shaped specimens (T3 and T4) were used. These four specimen designs are shown in figure 1 and specimen dimensions are listed in table 2. In each case, the flange region is 5.0inches wide and the blade is 3.0 -inches tall. The flange region includes both flange and skin. $\mathrm{X}$ shaped specimens actually represent two blade stiffeners glued back-to-back. This approach was used for the thinnest-skin specimens to prevent premature buckling of the skin region. Four blade thicknesses were considered. These specimens are not optimum designs, but comparison between test data and analytical predictions are used to verify the accuracy of the analysis. A total of twelve specimens were fabricated. Prior to testing, each end of the specimen was potted in 1.0-inch-deep epoxy compound and the ends were ground flat and parallel to each other to ensure uniform load introduction.

\section{Test Procedure and Instrumentation}

Specimens were loaded in axial compression in several test machines to accommodate the anticipated failure loads. Six control specimens (no initial damage) were loaded to failure. Six specimens were subjected to low-speed impact damage prior to compressive loading to failure. Load rates varied among the different tests, but generally tests were planned to run for 15-30 minutes. Data were recorded at the rate of once every second as load was applied during each test.

Displacements were measured using two displacement transducers measuring end-shortening, and two measuring out-of-plane displacement at the midlength location of the blade and flange. Out-ofplane measurements were at the edge of the flange and blade, as shown in figure 2. Back-to-back strain gages were used to monitor strains in the flanges and blades. Each specimen had between 16 and 24 strain gages. Typical strain gage and displacement measurement locations are shown in figure 2. One blade and one flange of each $\mathrm{X}$-shaped specimen was painted white to improve photographic quality. The unstiffened side of each T-shaped specimen was also painted white. Buckling load and failure locations were noted for each specimen.

\section{Impact Damage}

Six specimens were subjected to low-speed impact damage prior to loading to failure. An airpropelled aluminum projectile with 0.5 -inch diameter was used to inflict impact damage to the specimen blade with an energy level of approximately $20 \mathrm{ft}-1 \mathrm{~b}$. A low impact energy was selected because in an aircraft structure, a projectile would have to pass through the skin to get to the blade, resulting in a lower energy level on the blade compared to the external wing surface. Impacts were applied in either a normal or a 45-degree direction to the edge of the blade. A photograph of this damage corresponding to a 45-degree impact direction is shown in figure 3 for a specimen with configuration $\mathrm{X} 1$.

\section{Finite Element Analysis}

A finite element analysis of each specimen configuration with no impact damage was conducted using the finite element code STAGS. ${ }^{6}$ The analysis accounts for geometric nonlinearities but not plasticity. A buckling load was calculated based on a linear prebuckling stress state. Then a nonlinear analysis was conducted and buckling mode shapes were calculated based on the nonlinear stress state. Then an assumed initial imperfection in the shape of the buckling mode corresponding to the minimum buckling load was input. An imperfection mode with an amplitude of 0.001 -inches was input for each specimen to trigger nonlinear behavior for loads equal to and greater than the buckling load.

All structural components are modeled using quadrilateral shell elements. The finite element model for a $\mathrm{X}$-configuration specimen is shown in figure $4 \mathrm{a}$ and has 7,820 nodes and 7,644 elements, for a total of 46,920 degrees of freedom. The model for a T-configuration specimen is shown in figure $4 \mathrm{~b}$. T-configuration models contain 5,705 nodes, 5,551 elements and 34,230 degrees of freedom.

All degrees of freedom on one end of the specimen were restrained. For a region of one inch from each end, i.e., inside the potted region, all degrees of freedom were restrained except for the shortening of the specimen. A load was applied on one end of the specimen and all nodes on that end were constrained to move the same amount. The potting material was not modeled.

Each configuration was first analyzed to determine the linear, nonlinear and buckling behavior using assumed properties for each stack of material as one unit. Then a progressive failure analysis was conducted for specimens with configurations X1, X2 and T3 using the STAGS finite element code to determine the load at which the first element would sustain damage. Properties 
for each ply in each stack were used in the failure analysis. The additional input required for using this technique is described in reference 6 . Results obtained using a similar method are presented in references 7 and 8 for other structures and illustrate the failure prediction capability of this method. Ply properties used in this crippling study are the same as those used in reference 8 and are given in table 3 . This failure prediction method evaluates the strains and stresses in all plies in all elements and compares these values to the defined failure values. As the failure values are exceeded, appropriate ply level material properties are degraded and the ply loses its ability to carry load as the load to the structure is increased. Analytical results are obtained by examining the amount of damage and the location of damaged elements within the specimen at each load step. Each element in a model contains numerous locations where the stress and strain are calculated. The amount of damage in an element is expressed in terms of the percentage of these points which have stresses in excess of the input failure value.

\section{$\underline{\text { Results and Discussion }}$}

Analytical and experimental results are presented for all four specimens configurations. Analytical results are represented by solid lines and experimental results are represented by dashed lines. A summary of results for the control specimens is shown in table 4.

\section{Displacement and Buckling Loads}

Experimental and analytical results for endshortening and blade out-of-plane deformation are shown in figures 5-8 for configurations 1-4, respectively. Specimen end-shortening results agree well in each case. Out-of-plane deformation of the blades also agree well in the prebuckling range but experimental results indicate more displacement than analystical results in the postbuckling range for configurations X2 and T3.

Calculated and experimentally determined buckling loads for control specimens are presented in table 4. The analytical buckling loads for specimen configurations $\mathrm{X} 2$ and $\mathrm{T} 3$ are greater than the experimental buckling loads. The displacement results indicate that while the analysis accurately predicts the postbuckling stiffness of the specimens, the postbuckling displacement in specimens $\mathrm{X} 2$ and $\mathrm{T} 3$ is in error because the predicted buckling load is greater than the experimental buckling load. Buckling mode shapes from finite element analysis for configurations $\mathrm{X} 1, \mathrm{X} 2$, and $\mathrm{T} 3$ are shown in figures 9-11, respectively. The analytical buckling load for configuration $\mathrm{T} 4$ is significantly greater than the load at which failure occurred. Analytical results indicate that no failures occur in specimens with configurations $\mathrm{X} 1, \mathrm{X} 2$ or T3 prior to buckling.

\section{$\underline{\text { Strain }}$}

The first specimen with configuration $\mathrm{X} 1$ was loaded to $60,000 \mathrm{lb}$, unloaded and then loaded to failure. Experimental and analytical strains at the midlength location of the blade at its tip for configuration 1 are shown in figure 12. There is excellent agreement between strain gage results and experimental predictions, indicating the accuracy of the predicted buckling load of $20,000 \mathrm{lb}$. The axial and lateral strains throughout the specimen as determined from finite element analysis are shown in figure 13. The axial strains at an applied load of 72,000 lb, range from an axial compressive strain of $-0.015 \mathrm{in} / \mathrm{in}$. to a tensile strain of $0.0085 \mathrm{in} . / \mathrm{in}$. Lateral strains range from a compressive strain of $-0.01 \mathrm{in} . / \mathrm{in}$. to a tensile strain of $0.009 \mathrm{in} . / \mathrm{in}$. The value of $72,000 \mathrm{lb}$ corresponds approximately to the experimental failure load of the specimen. Allowable compressive strain would be less than $0.0089 \mathrm{in.} / \mathrm{in}$. and allowable tensile strain would be 0.0121 , with failure predictions of approximately $15 \%$ higher than the allowables.

Using the individual ply properties rather than stack properties in the progressive failure analysis allows for a more detailed prediction of failure. The buckling load was unaffected by the change in properties. The progressive failure analysis of a specimen with configuration $\mathrm{X} 1$ indicates that no damage would occur for load less than $30,000 \mathrm{lb}$, or 1.5 times the buckling load. Damage initiates in the blade mid-length, where the blade joins the flange, as shown in figure 14a. Damage progresses to include the center of the blade and then the corners at the edge of the potted region of the flange. Damaged regions at an applied load of 2.7 times the buckling load are shown in figure 14b. The shades in figure 14 represent the amount of damage in each element. Each element in the model contains numerous locations where the stress and strain are calculated. The amount of damage in an element is expressed in terms of the percentage of these points which have stresses in excess of the input failure value. No element is more then 25 percent failed at an applied load of 2.7 times the buckling load.

Primary failure of the test specimen is along the axial centerline in the blade and flange. In addition, the bond between the two flange pieces at the edge failed, as shown in figure 15 . The finite element analysis assumes a perfect bond and has no means to evaluate through-thethickness failures. The failure load, however, is more than three times the buckling load. After the specimen blades buckle, the load is concentrated in the flange and at the 
intersection of the flange and blade. Therefore, it is to be expected that the specimen would fail at these locations.

Experimental and analytical strains at the midlength location of the blade at the tip for the control specimen of configuration $\mathrm{X} 2$ are shown in figure 16. There is good agreement between strain gage results and experimental predictions. The initial failure location is predicted to be at the junction between the flange and blade at the specimen midlength. In the experiment, primary failure is in the bond between the two flange pieces at the edge. The finite element analysis assumed a perfect bond and had no means to evaluate through-the-thickness failures. Analysis results indicate that initial failure would begin at an applied load approximately 1\% greater than the buckling load and $5 \%$ of the elements would have damage at an applied load of 1.2 times the buckling load. The experimental failure load is approximately 1.2 times the buckling load. This damage progression is shown in figure 17.

Experimental and analytical strains at the midlength location of the blade at the tip for the control specimen with configuration $\mathrm{T} 3$ are shown in figure 18. There is good agreement between strain gage results and experimental predictions. Analysis results indicate that the first ply damage would occur at an applied load approximately equal to the analytical buckling load. The first element to show damage is in the corner of the flange at the edge of the potting. The specimen failed at a location that is approximately one fourth of the distance between the potting regions at a load just past buckling, as shown in figure 19.

Experimental and analytical strains at the midlength location of the blade at the tip for configuration T4 are shown in figure 20. Excellent agreement is seen between strain gage results and experimental predictions. Analysis indicates that the maximum stress values are found at the intersection of the blade and flange at the edge of the potting region. As predicted, specimens with this configuration did not buckle prior to failure.

\section{Structural Efficiency of Stiffened Panels}

Structural efficiency is expressed in terms of weight versus load carrying capability. In the past, these values would be based on global or local buckling with no load carrying capability considered for loads greater than the buckling load. However, since the purpose of this study is to evaluate the potential weight savings of allowing panels to buckle prior to ultimate load, buckling is not considered to be the maximum allowable load. A maximum strain failure criterion is used such that strains may not exceed the allowable strains presented in table 1 . To eliminate the effects of length, efficiency is expressed herein as weight/planform area (W/A) vs. running load $\left(\mathrm{N}_{\mathrm{x}}\right)$, as discussed in reference 3 . Using this format, the lower a specimen weight ratio, the more structurally efficient. Values are shown based on three assumptions: 1) no buckling is permitted at loads less than ultimate load, 2) buckling is permitted for loads greater than design limit load only, and 3) buckling is permitted at any load and ultimate load is determined by other means. Obviously, the last of these options may produce the most efficient structure, but it may be impractical for aerodynamic or other reasons to allow buckling at less than limit load.

The design for configurations X1, X2 and T3 were extrapolated to a 21 -inch-wide panel with a 7 -inch stiffener spacing. Blade dimensions were left unchanged but skin regions (without flanges) were assumed to be 3inches wide. All panels were assumed to be 12-inches long and held between clamped loaded edges. Unloaded edges were assumed to be free. All panel blades are the same thickness as the corresponding crippling configuration. Skin thickness is 0.11 -inches for all panels. Flange thickness is half the blade thickness for panels corresponding to $\mathrm{X}$-shaped crippling specimens. Flange and skin thickness together equal the flange region thickness for the T-shaped crippling specimens. A sketch of the panel configuration is shown in figure 21 and the skin, blade and flange thicknesses corresponding to each crippling specimen configuration are shown in table 5 . Efficiency results are based on finite element analysis of the panel to calculate buckling loads and damage progression assumed to match the damage progression of the corresponding crippling specimen. The buckling load for the panel with stiffener configuration 1 is $38,588 \mathrm{lb}$, or $1,837 \mathrm{lb} / \mathrm{in}$. across the $21 \mathrm{inch}$ width. The corresponding buckling load for the crippling specimen with configuration 1 is $2,030 \mathrm{lb} / \mathrm{in}$. across the 5 -inch width (the X-configuration is two back-to-back stiffeners). The buckling load for the panel with stiffener configuration 2 is $128,888 \mathrm{lb}$, or $6,137 \mathrm{lb} / \mathrm{in}$. The corresponding buckling load for the crippling specimen with configuration X2 is $14,900 \mathrm{lb} / \mathrm{in}$. Critical loads are shown for panels corresponding to configurations X1, X2 and T3 in table 6 . For configurations $\mathrm{X} 1$ to $\mathrm{T} 3$, efficiencies based on the assumption that ultimate load is the buckling load and that the ultimate load is 1.5 times the buckling load are shown in figure 22. Also shown are predictions assuming the ultimate load is the load at the first damage event (based on the load of the first damage event in the crippling specimen) and assuming that the ultimate load is the load when $5 \%$ of the elements are damaged (based on the crippling specimen). For configuration 1 , the first damage event occurs at 1.5 times the buckling load but damage does not progress to encompass $5 \%$ of the elements until 2.7 times the buckling load. An increase in load of $50 \%$ can be achieved by allowing the panel to 
buckle at limit load rather than at ultimate load. Alternately, a thinner, lighter specimen could be designed to carry the original ultimate load. For configuration 2, the first damage event occurs at 1.1 times the buckling load and damage progresses to $5 \%$ of the elements at 1.2 times the buckling load. For configuration T3, the first damage event is at buckling, so further damage progression is not evaluated. Since the crippling specimen with configuration $\mathrm{T} 4$ failed prior to buckling, no results for a comparable panel are presented. Buckling and damage loads are presented in table 6. Displacement patterns for panels with configuration X1 at a load of 1.5 times the buckling load is shown in figure 23 . Strain contours for this panel are shown in figure 24 .

\section{Effect of impact damage}

The failure load for both control and impactdamaged specimens is greater than 1.5 times the buckling load only for configuration X1. In fact, the impact-damaged specimens with configurations $\mathrm{X} 2$, $\mathrm{T} 3$, and T4 failed prior to buckling. Therefore, the impact is more critical than buckling in these three configurations so buckling is not the driving factor in designing panels with these restrictions. Efficiency cannot be improved by allowing a lower buckling load unless impact damage is not a design criterion. Specimen failure loads are summarized in table 7 .

For the most lightly loaded configuration, configuration 1 , the failure loads of the control and impact specimens are approximately the same so impact is not the critical factor. Buckling load is a critical factor so structural efficiency is driven by buckling and, therefore, can be improved by allowing buckling at loads less than design ultimate load.

\section{Concluding Remarks}

The structural efficiency of blade-stiffened stitched specimens is compared to determine their weight saving potential if stiffeners of composite aircraft wings were allowed to buckle at loads less than design ultimate load. Four configurations of crippling specimens were examined experimentally and by using finite element analysis. Analytical and experimental results are in good agreement. Once buckling, stress and impact damage are considered, only the specimen configuration with the thinnest blade and skin demonstrated significant potential weight-savings by allowing a post-buckled design. All other configurations failed at loads less than or near the buckling load. The lightly loaded specimen configuration would be useful in less stressed wing sections, such as near the wing tip, where a stiffener and/or skin could be allowed to buckle at load as low as design limit load without failure to any part of the wing.

\section{$\underline{\text { References }}$}

1. Karal, M, "AST Composite Wing Program Executive Summary," NASA CR 2001-210650.

2. Williams, J., Anderson, M., Rhodes, M., Starnes, J., and Stroud, J., "Recent Developments in the Design, Testing and Impact-Damage Tolerance of Stiffened Composite Panels." NASA TM 80077.

3. Jegley, D., "Study of Compression-Loaded and Impact Damaged Structurally Efficient GraphiteThermoplastic Trapezoidal-Corrugation Sandwich and Semisandwich Panels," NASA TP 3264, 1992.

4. Markus, A., Thrash, P., and Grossheim, B., "Manufacturing Development and Requirements for Stitched/RTM Wing Structure," NASA CP 3229, 1993, pp. 503-523.

5. Rohwer, K., Ghumman, A., and Markus, A., "Stitched/Resin Film Infusion (S/RFI) Manufacturing Technology Development," Proceedings of the $11^{\text {th }}$ DOD/NASA/FAA Conference on Fibrous Composites in Structural Design. Report number WL-TR-97-3009 pp. XIII-93-116.

6. Rankin, C. C., Brogan, F. A, Loden, W. A., and Cabiness, H. D., "STAGS User Manual, Version 4.0." Lockheed Martin Missiles and Space Company, Incorporated, May 2001

7. Sleight, D.W., Knight, N. F., Wang, J. T., "Evaluation of a Progressive Failure Analysis Methodology for Laminated Composite Structures," Presented at the AIAA/ASME/ASCE/AHS/ASC $38^{\text {th }}$ Structures Structural Dynamics and Materials Conference, 1997.

8. McGowan, D. M., Davila, C. G., and Ambur, D. R., "Damage Progression in Buckle-Resistant Notched Composite Plates Loaded in Uniaxial Compression," Presented at the AIAA/ASME/ASCE/AHS/ASC $42^{\text {nd }}$ Structures Structural Dynamics and Materials Conference, 2001. 
Table 1. Material stack properties

\begin{tabular}{ll}
\hline \hline Longitudinal stiffness, msi & 9.25 \\
Transverse stiffness, msi & 4.67 \\
Shear stiffness, msi & 2.27 \\
Major Poisson's ratio & 0.397 \\
Stack thickness, in. & 0.055 \\
Allowable compressive strain, in./in. & -0.0089 \\
Allowable tensile strain, in./in. & 0.0121 \\
Density, lb/in & 0.057 \\
\hline \hline
\end{tabular}

Table 2. Nominal specimen dimensions

\begin{tabular}{clll}
\hline \hline Configuration & $\begin{array}{l}\text { Blade } \\
\text { thickness } \\
\text { (in.) }\end{array}$ & $\begin{array}{l}\text { Flange region } \\
\text { thickness } \\
\text { (in.) }\end{array}$ & $\begin{array}{l}\text { Length } \\
\text { between } \\
\text { potting } \\
\text { (in.) }\end{array}$ \\
\hline X1 & 0.11 & 0.22 & 10. \\
X2 & 0.22 & 0.44 & 11. \\
T3 & 0.33 & 0.33 & 11. \\
T4 & 0.44 & 0.44 & 12. \\
\hline \hline
\end{tabular}

Table 3. Nominal ply properties

\begin{tabular}{lccc}
\hline \hline & $0^{\circ} \mathrm{ply}$ & $+45^{\circ}$ and $-45^{\circ}$ ply & $90^{\circ}$ ply \\
\hline Longitudinal stiffness, Msi & 16.43 & 16.15 & 15.97 \\
Transverse stiffness, Msi & 1.60 & 1.60 & 1.60 \\
Shear stiffness, Msi & 0.80 & 0.80 & 0.80 \\
Major Poisson's ratio & 0.34 & 0.34 & 0.34 \\
Ply thickness, in. & 0.0061 & 0.0061 & 0.0061 \\
Failure compresive longitudnal stress, ksi & 175 & 175 & 175 \\
Failure tensile longitudinal stress, ksi & 257 & 231 & 213 \\
Failure compresive transverse stress, ksi & 36.5 & 36.5 & 36.5 \\
Failure tensile axial transerse, ksi & 5.88 & 5.88 & 5.88 \\
Failure shear stress, ksi & 20.6 & 20.6 & 20.6 \\
\hline \hline
\end{tabular}

Table 4. Behavior of control specimens

\begin{tabular}{|c|c|c|c|c|c|c|c|}
\hline \multirow[t]{3}{*}{$\begin{array}{l}\text { Config- } \\
\text { uration }\end{array}$} & \multicolumn{2}{|c|}{$\begin{array}{c}\text { Buckling load } \\
\text { (kips) }\end{array}$} & \multicolumn{3}{|c|}{$\begin{array}{l}\text { Failure load } \\
\text { (kips) }\end{array}$} & \multirow{2}{*}{\multicolumn{2}{|c|}{$\begin{array}{c}\begin{array}{c}\text { Ratio of damage load to } \\
\text { bucking load }\end{array} \\
\text { Analysis }\end{array}$}} \\
\hline & \multirow{2}{*}{$\begin{array}{c}\text { Experi- } \\
\text { ment }\end{array}$} & \multirow[t]{2}{*}{ Analysis } & Experiment & \multicolumn{2}{|c|}{ Analysis } & & \\
\hline & & & Final failure & $\begin{array}{l}\text { Initial } \\
\text { damage }\end{array}$ & $\begin{array}{c}5 \% \text { of elements } \\
\text { damaged }\end{array}$ & $\begin{array}{c}\text { Initial } \\
\text { damage }\end{array}$ & $\begin{array}{c}5 \% \text { of elements } \\
\text { damaged }\end{array}$ \\
\hline $\mathrm{X} 1$ & 20 & 20 & 71 & 30 & 55 & 1.5 & 2.7 \\
\hline $\mathrm{X} 2$ & 125 & 149 & 192 & 152 & 186 & 1.0 & 1.2 \\
\hline $\mathrm{T} 3$ & 140 & 166 & 150 and $154^{*}$ & 166 & & 1.0 & \\
\hline $\mathrm{T} 4$ & none & 359 & 231 and $254^{*}$ & 251 & & 0.7 & \\
\hline
\end{tabular}

Two control specimens were tested 
Table 5. Panel geometry

\begin{tabular}{llcc}
\hline \hline Configuration & $\mathrm{X} 1$ & $\mathrm{X} 2$ & $\mathrm{~T} 3$ \\
\hline Blade thickness (in.) & 0.11 & 0.22 & 0.33 \\
Flange thickness (in.) & 0.055 & 0.11 & 0.22 \\
Skin thickness (in.) & 0.11 & 0.11 & 0.11 \\
Skin and flange region (in.) & 0.165 & 0.22 & 0.33 \\
\hline \hline
\end{tabular}

Length is 12 inches, width is 21 inches, stiffener spacing is 7 inches

Table 6. Panel buckling and failure loads

\begin{tabular}{cccc}
\hline \hline Configuration & Buckling load (lb) & $\begin{array}{c}\text { Critical running } \\
\text { load } \\
(\mathrm{lb} / \mathrm{in})\end{array}$ & $\begin{array}{c}\text { Panel failure load based on } \\
\text { crippling specimen } \\
(\mathrm{l})\end{array}$ \\
\hline $\mathrm{X} 1$ & 38,588 & 1,837 & 100,328 \\
$\mathrm{X} 2$ & 128,888 & 6,137 & 166,083 \\
$\mathrm{~T} 3$ & 262,303 & 12,490 & 284,786 \\
\hline \hline
\end{tabular}

Table 7. Failure loads of control and impact-damaged specimen

\begin{tabular}{ccc}
\hline \hline Configuration & \multicolumn{2}{c}{$\begin{array}{c}\text { Failure load } \\
\text { (kips) }\end{array}$} \\
& Control & Impact damaged \\
\hline X1 & 71 & 73 \\
X2 & 192 & 176 \\
T3 & 150 and $154^{*}$ & 137 and $141^{*}$ \\
T4 & 231 and $254^{*}$ & 193 and $218^{*}$ \\
\hline
\end{tabular}

* Two specimens were tested

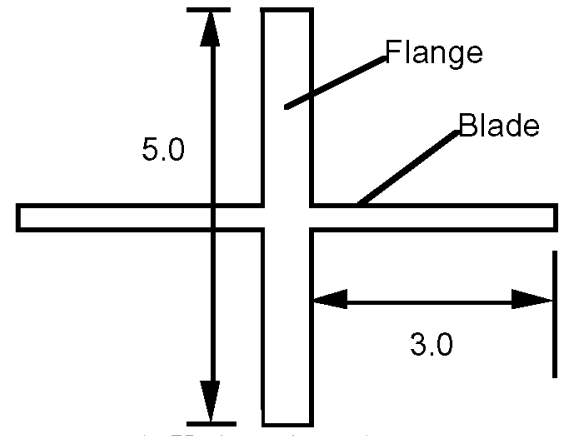

a) X-shaped specimen

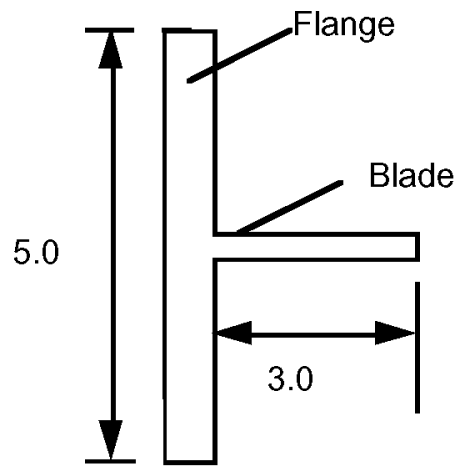

b) T-shaped specimen

Fig. 1. Test specimen geometry. All dimensions are in inches. 


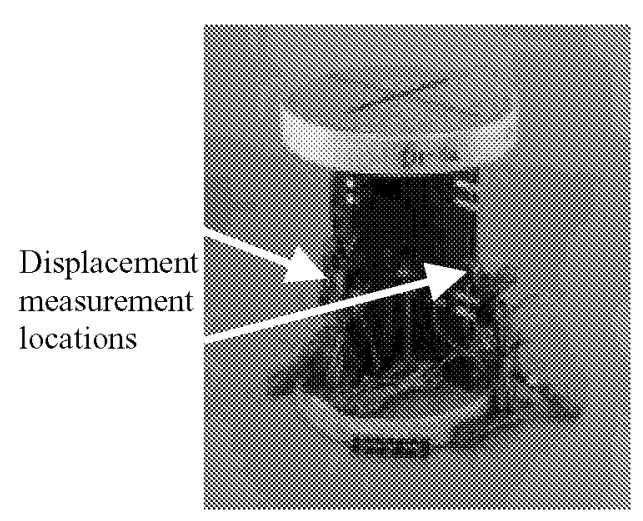

a) X-shaped specimen

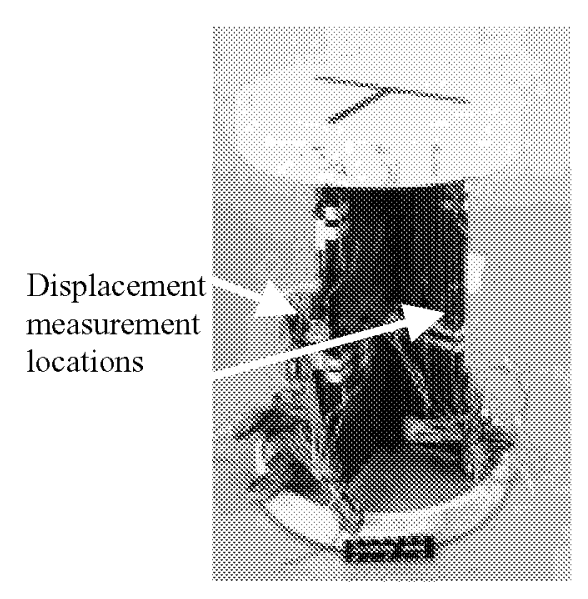

b) T-shaped specimen

Fig. 2. Strain gage and displacement measurement locations.

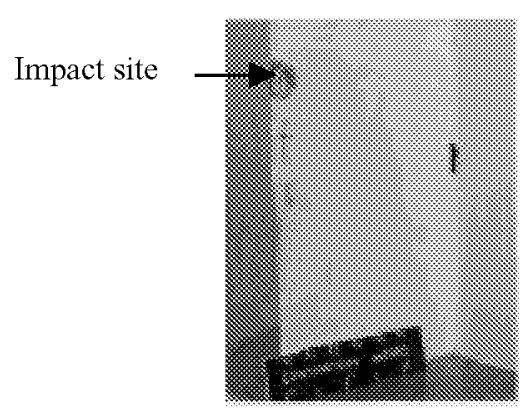

Fig. 3. Impact damage.

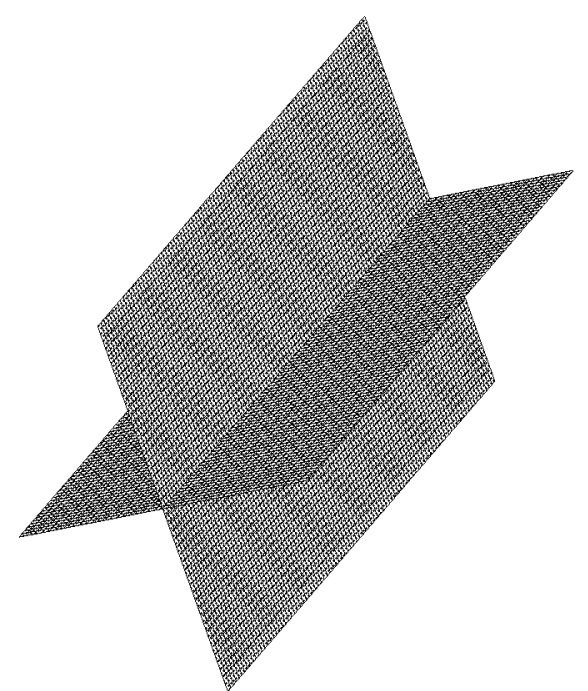

a) X-shaped specimen

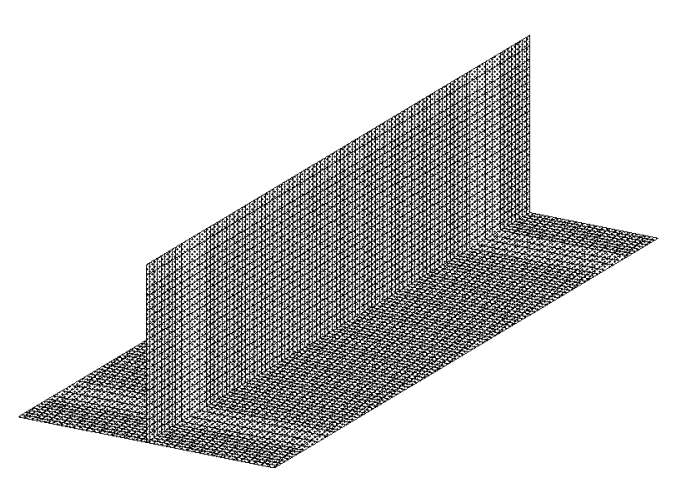

b) T-shaped specimen

Fig. 4. Finite element models.

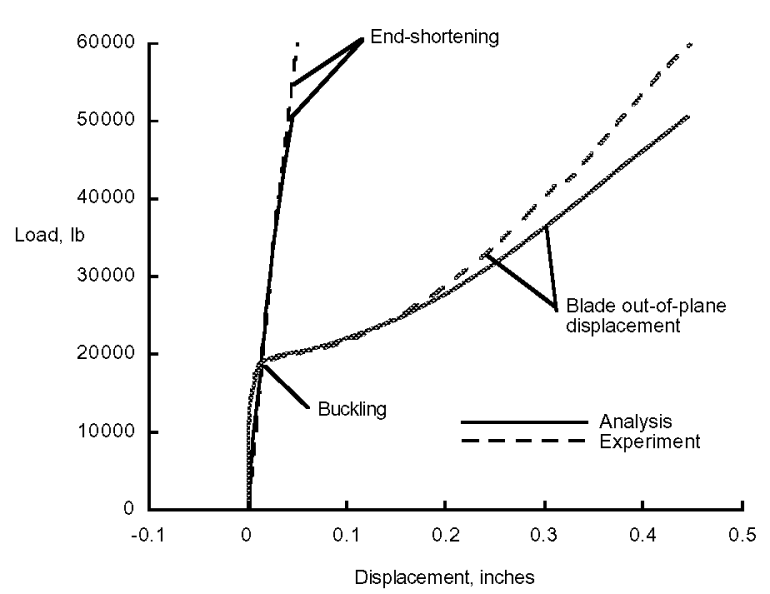

Fig. 5. Measured and predicted displacements for configuration $\mathrm{X} 1$ control specimen. 


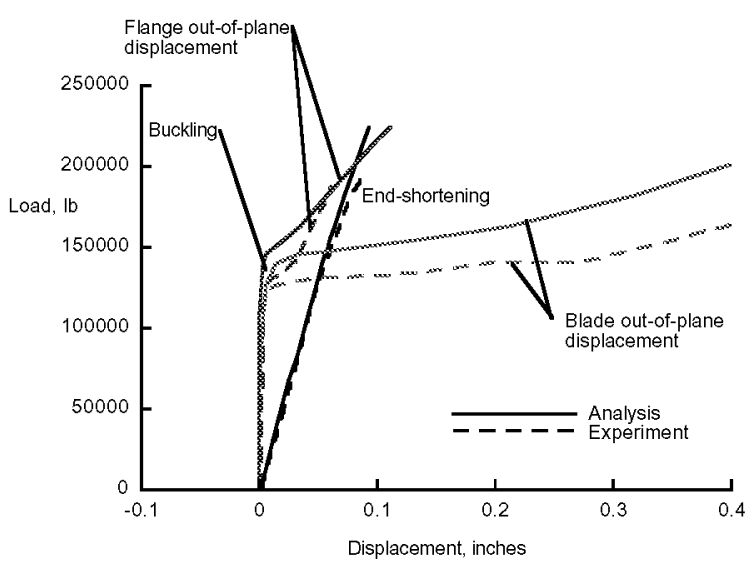

Fig. 6. Measured and predicted displacements for configuration $\mathrm{X} 2$ control specimen.

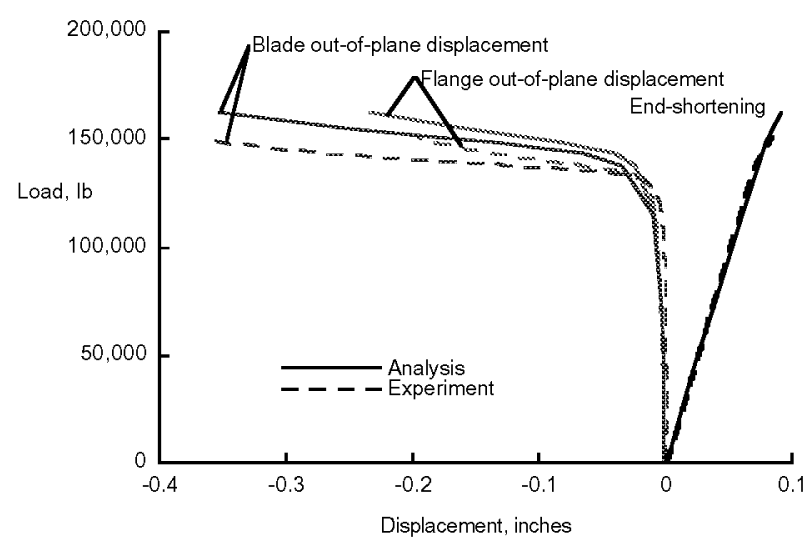

Fig. 7. Measured and predicted displacements for configuration T3 control specimen.

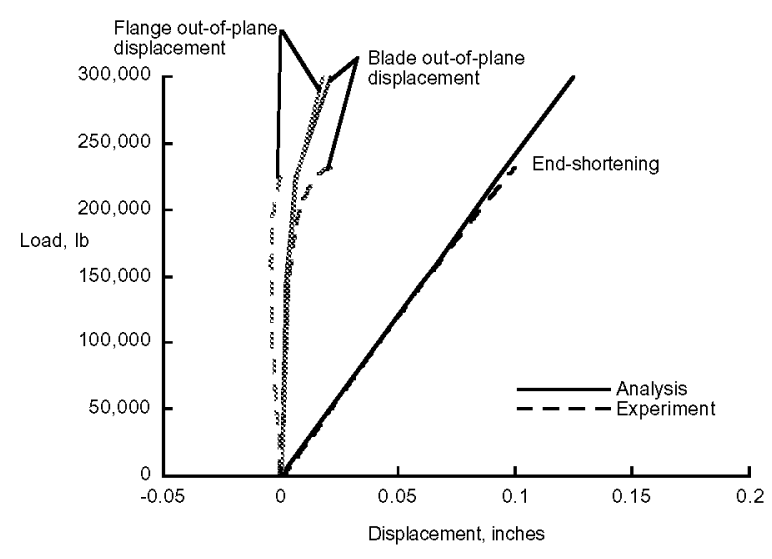

Fig. 8. Measured and predicted displacements for configuration T4 control specimen.

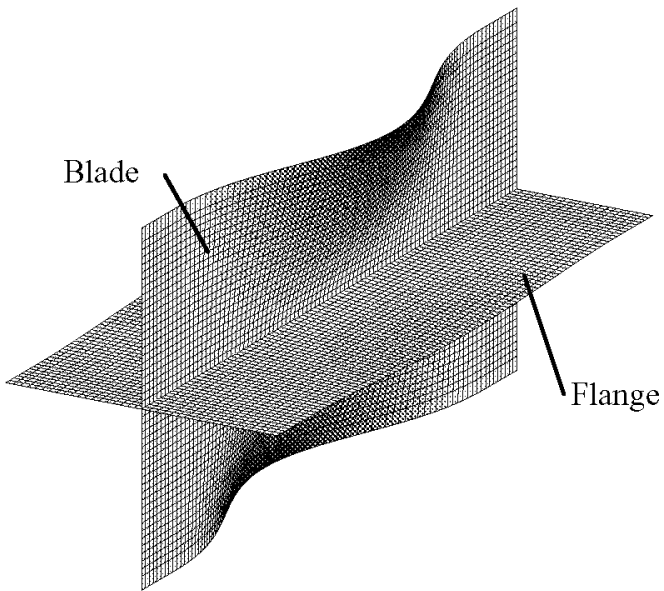

Fig. 9. Buckling mode shape for configuration X1 specimen.

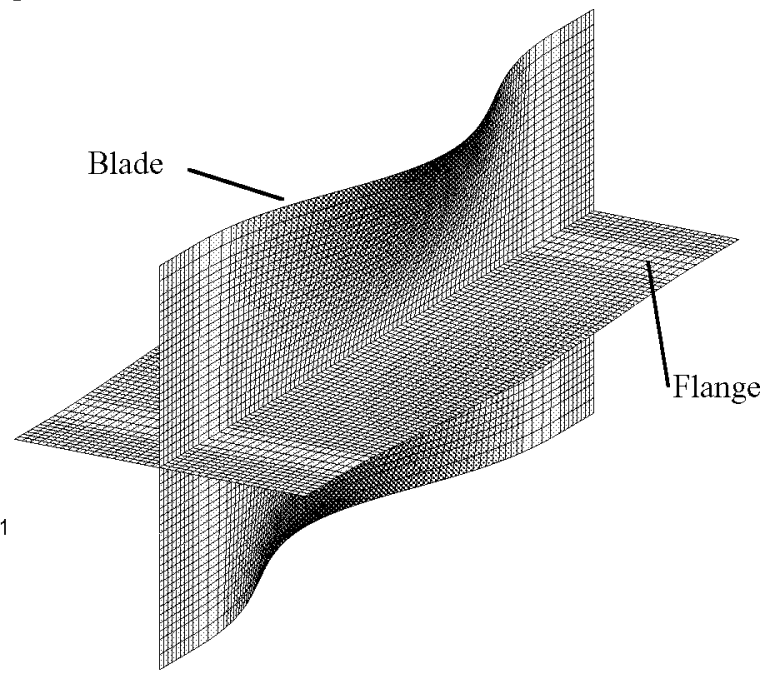

Fig. 10. Buckling mode shape for configuration X2 specimen.

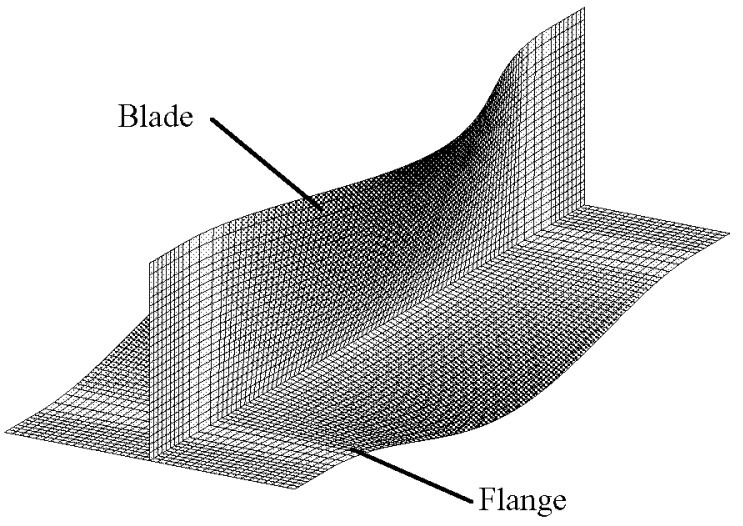

Fig. 11. Buckling mode shape for configuration T3 specimen. 


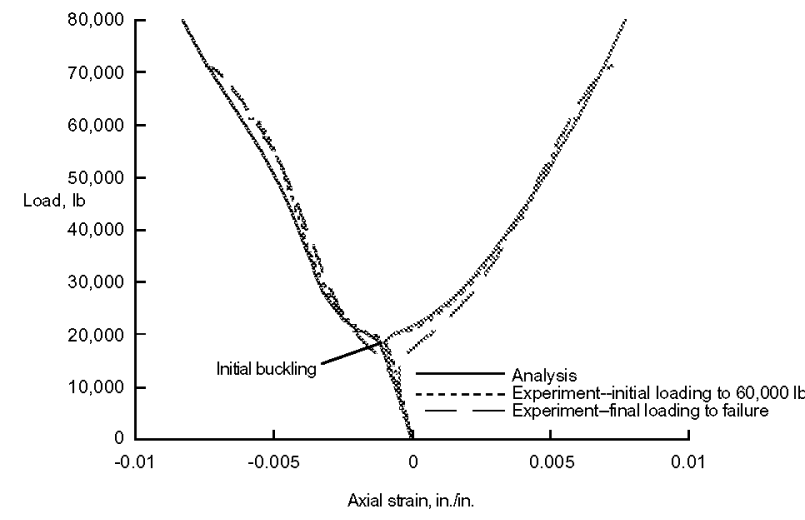

Fig. 12. Measured and predicted strains in blade of configuration X1 control specimen.

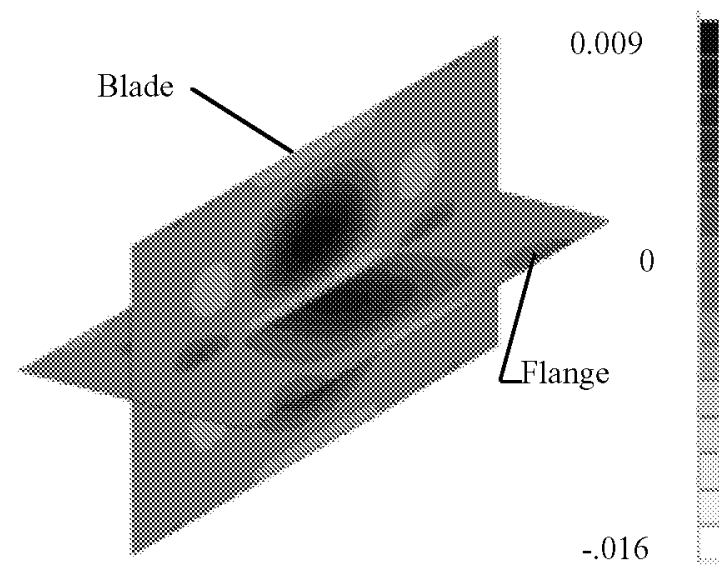

a) axial surface strain

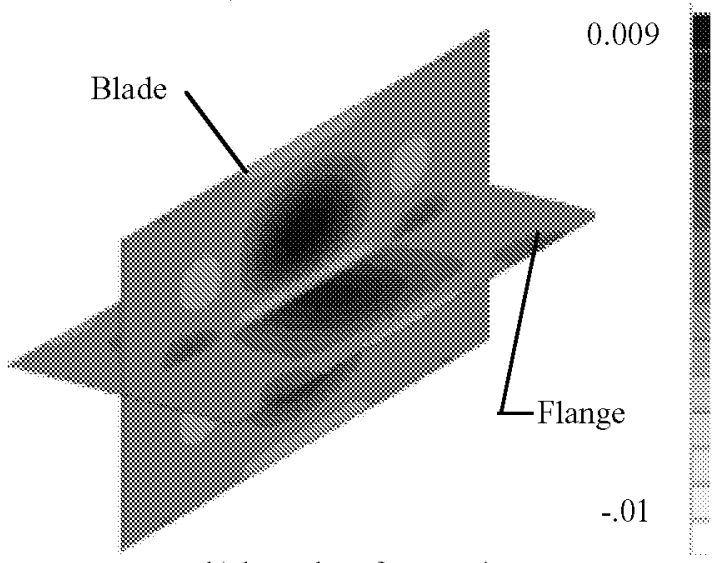

b) lateral surface strain

Fig. 13. Surface strain contours for configuration X1 specimen at an applied load of 72,000 lb.

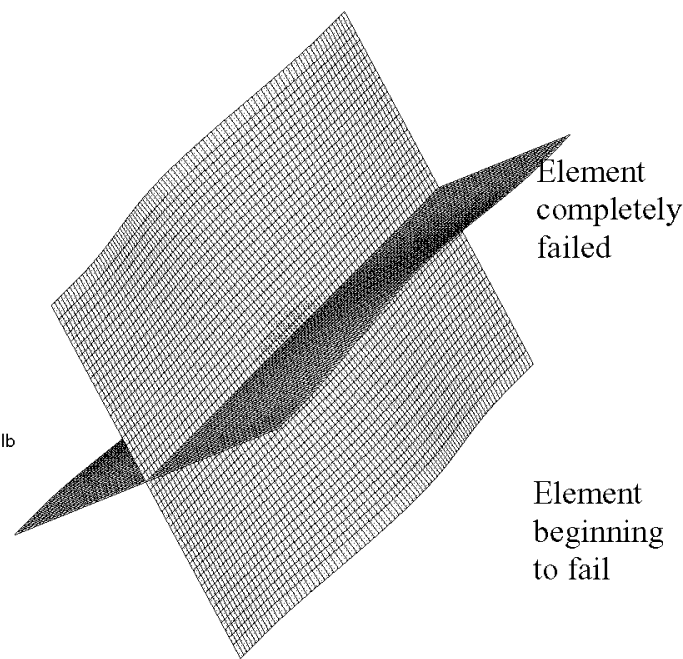

a) Damaged elements for an applied load of 2.0 times the buckling load

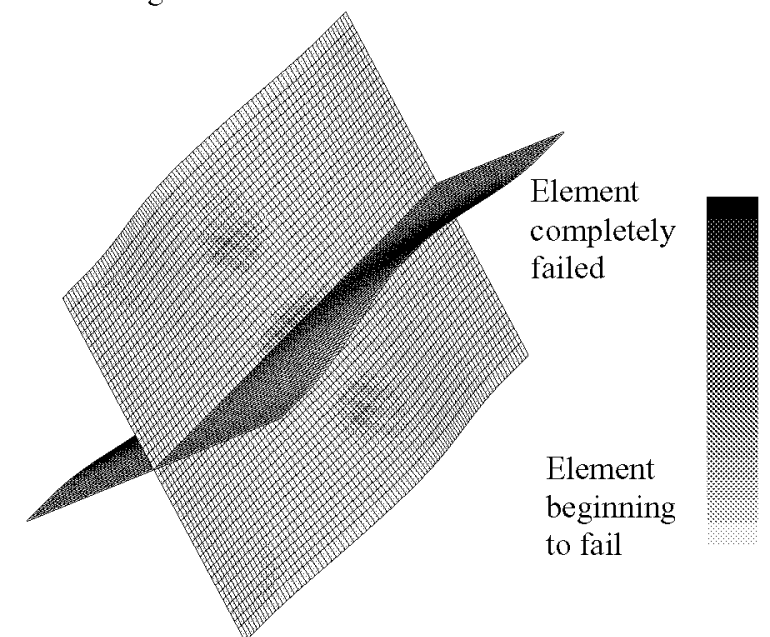

b) Damaged elements for an applied load of 2.7 times the buckling load

Fig. 14. Predicted locations of initial failures for configuration $\mathrm{X} 1$ specimen.

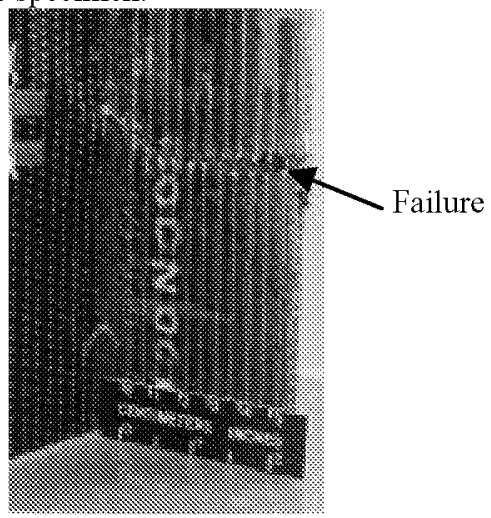

Fig. 15. Failed configuration X1 control specimen. 


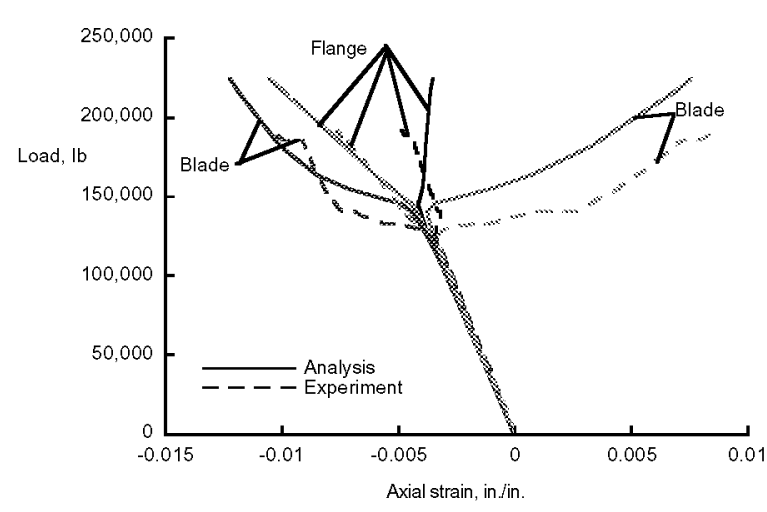

Fig. 16. Measured and predicted strains in blade and flange of configuration $\mathrm{X} 2$ control specimen.

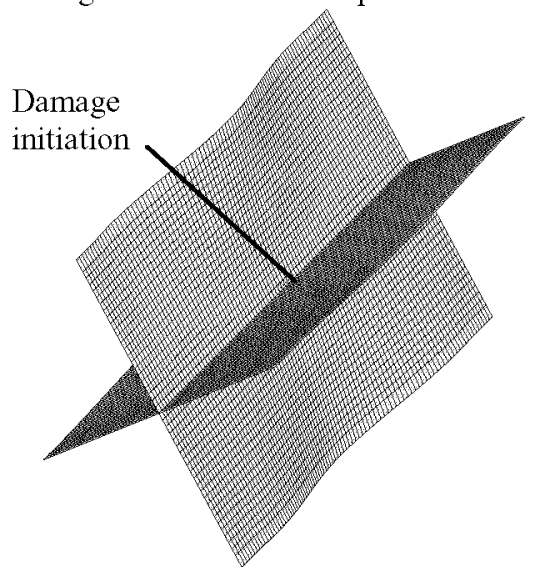

a) Initial damage for an applied load of 1.01 times the buckling load

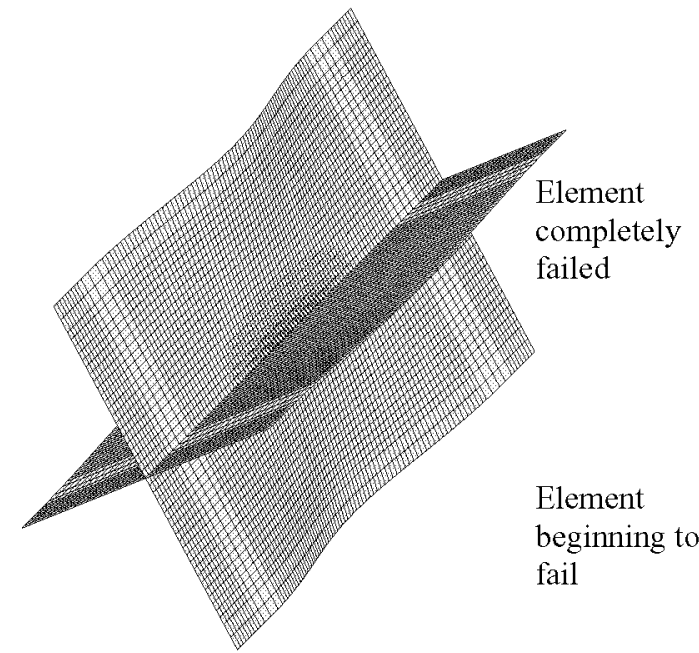

b) Damaged elements for an applied load of 1.28 times the buckling load

Fig. 17. Predicted failure locations for configuration X2 specimen.

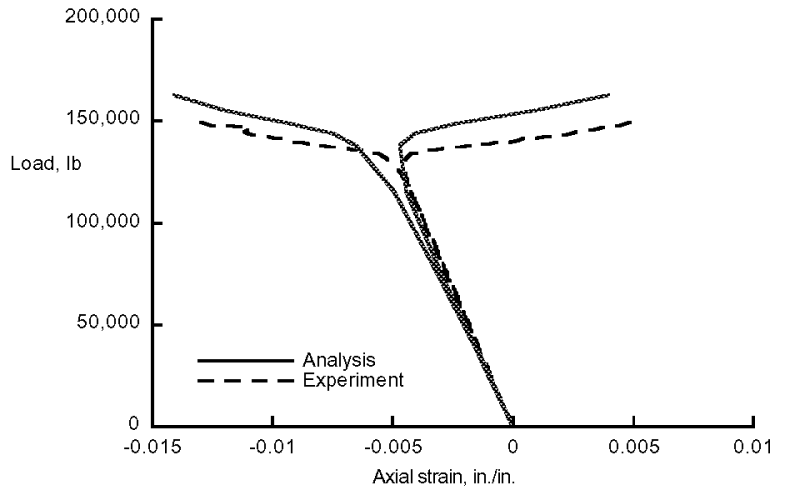

Fig. 18. Measured and predicted strains in blade midlength of configuration T3 control specimen.

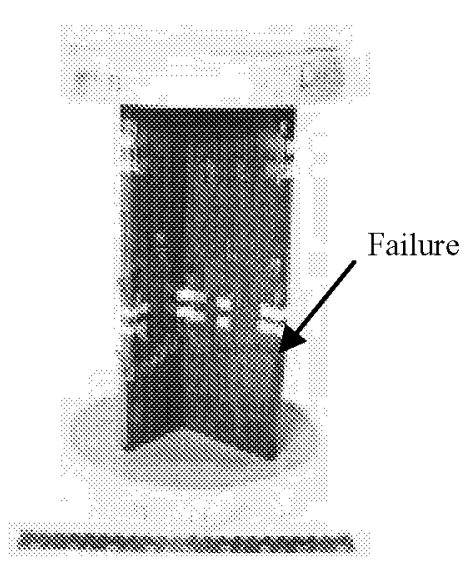

Fig. 19. Failed configuration T3 control specimen.

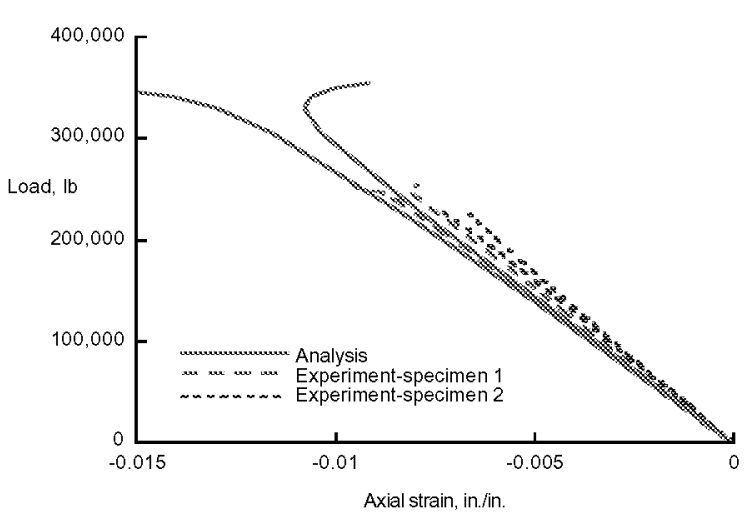

Fig. 20. Measured and predicted strains at the edge of potting in configuration T4 control specimens. 


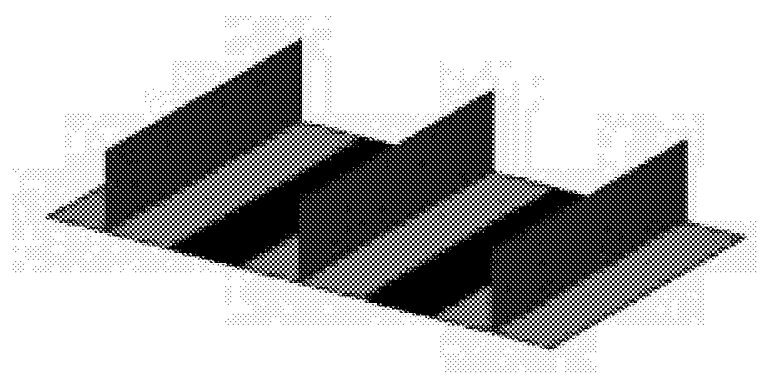

Fig. 21. Stiffened panel configuration. Dimensions shown in table 5.

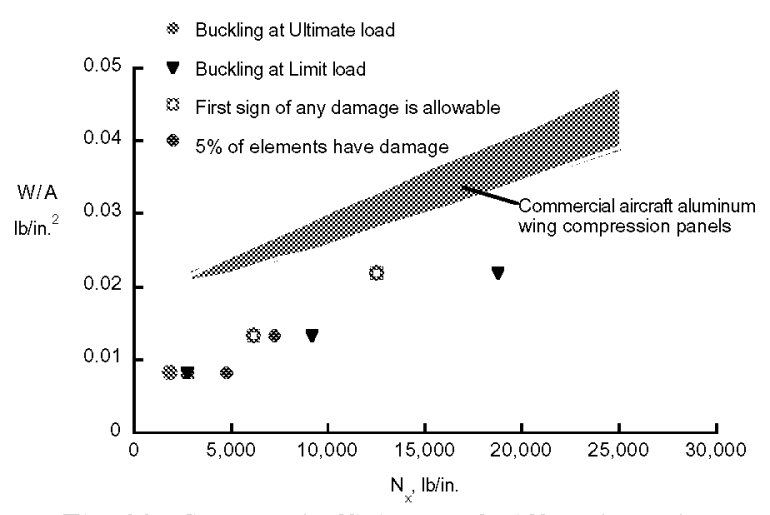

Fig. 22. Structural efficiency of stiffened panels.

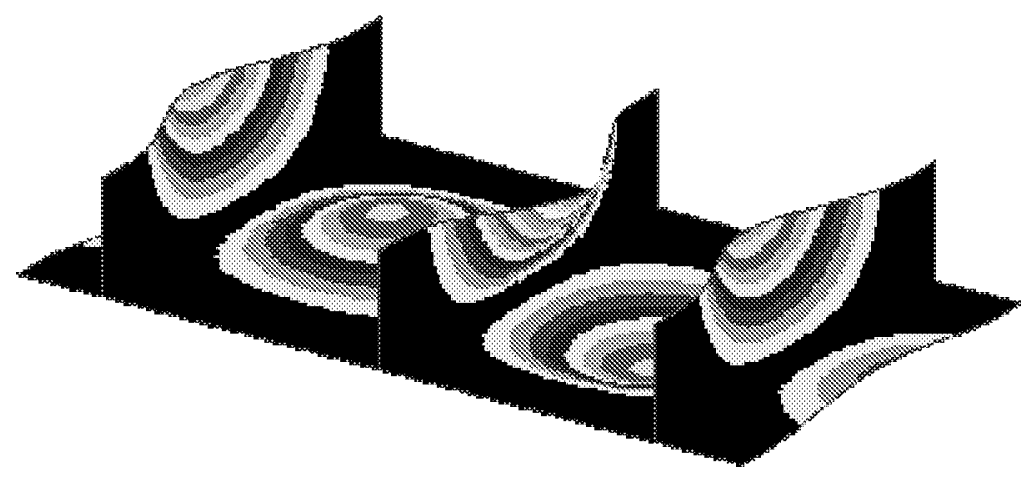

$-0.24$

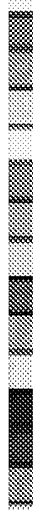

0.0

Fig. 23. Deformation pattern for panel with configuration X1 stiffeners at a load of 1.5 times the buckling load. Dimensions are in inches.
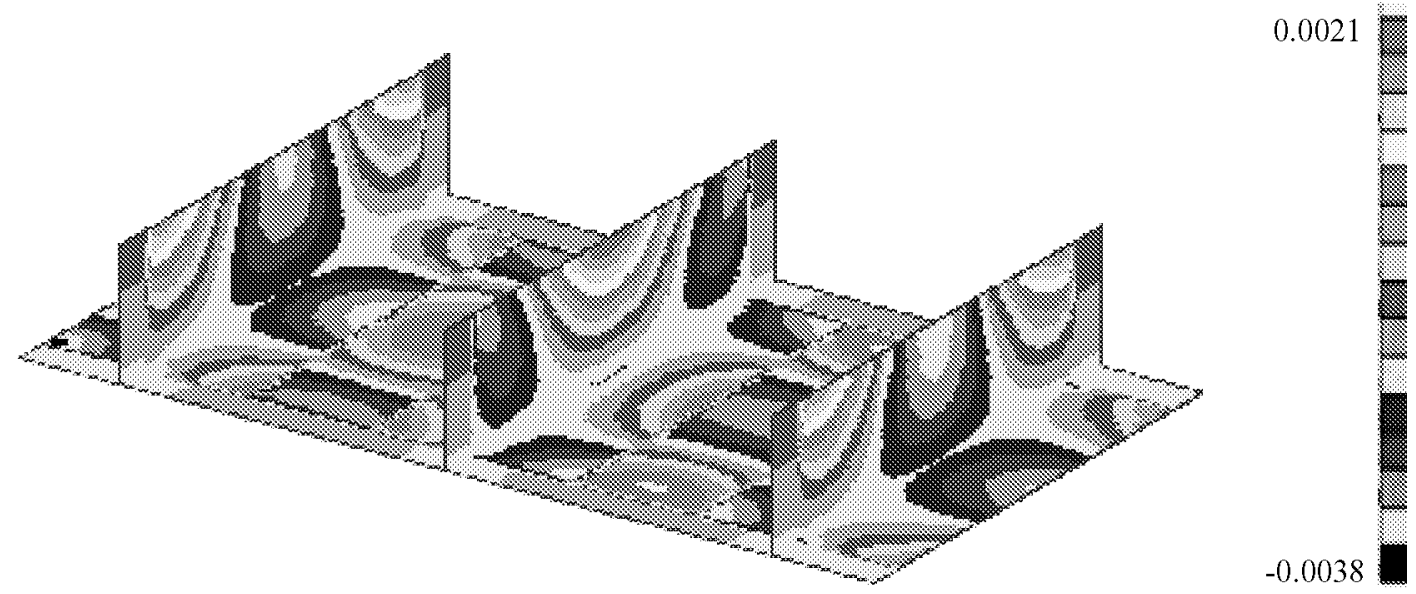

Fig. 24. Axial strain for panel with configuration X1 stiffeners at an applied load of 1.5 times the buckling load. 